\title{
Eritema multiforme asociado a herpes virus: reporte de caso
}

\author{
Anibal Manrique $\mathrm{A}^{1}$, Mayra Leiva $\mathrm{G}^{1}$, Mitchelle Linares $\mathrm{D}^{1}$, Yordan Martinez $\mathrm{E}^{1}$, Jean Carlo Mayta $\mathrm{C}^{1}$
}

\section{RESUMEN}

El eritema multiforme (EM) es una reacción de hipersensibilidad que afecta la piel y/o membranas mucosas, en respuesta a infecciones, medicamentos u otras comorbilidades. La presentación del EM puede ser Menor (EM leve, caracterizado por presentar lesiones “en diana”) o Mayor (EM severo, que ocurre además con compromiso de mucosas). Se reporta el caso de un paciente varón de 36 años de edad que acudió a emergencias del Hospital Nacional Arzobispo Loayza (HNAL) con fiebre, malestar general, lesiones pruriginosas y dolorosas de tipo ulcerosas en cavidad oral, múltiples lesiones en diana bilaterales en miembros superiores, inferiores, pene y región perianales. Por lo anterior, el diagnóstico fue de EM Mayor. Las lesiones ulcerosas en cavidad oral y en diana en manos eran las más resaltantes.

Palabras Clave: eritema multiforme, virus herpes simplex.

\section{Erythema multiform associated with herpes virus: case report}

\section{ABSTRACT}

Erythema multiforme (EM) is a hypersensitivity reaction that affects the skin and/or mucous membranes, in response to infections, drugs, or other comorbidities. Presentation of EM can be Minor (Mild EM, characterized for presenting target lesions) or Major (Severe EM, that occurs also with mucous membranes involvement). The case of a 36 year old male patient presenting to emergency of HNAL with fever, malaise, itching and painful ulcer type lesions in oral cavity, multiple target lesions in upper and lower limbs, penis, and perianal region is reported. The diagnosis was EM Major. Ulcerous lesions in oral cavity and target lesions in hands were the most salient.

Key words: erythema multiforme, virus herpes simplex.

1 Estudiantes de 6to año de la Facultad de Medicina Universidad de San Martín de Porres. Lima-Perú. 


\section{INTRODUCCIÓN}

El EM es un trastorno inmune de hipersensibilidad aguda que implica reacciones antígeno-anticuerpo que se dirigen a los pequeños vasos sanguíneos en la piel o en las mucosas, con la formación de ampollas, úlceras y lesiones papulares en diana distribuidas simétricamente en las extremidades y cara (1). La tasa de prevalencia del EM es inferior al $1 \%$ y su incidencia anual es desconocida $(2,3)$. El EEM suele producirse normalmente en los adultos jóvenes de 20 a 40 años de edad y existe discrepancia entre series sobre la prevalencia y relación entre hombres y mujeres $(3,4)$. En aproximadamente el $90 \%$ de los casos, el acontecimiento desencadenante es infeccioso, predominando la infección por el Virus Herpes Simplex (VHS), que juega un papel predominante en $70 \%$ a $80 \%$ de situaciones (5). Otros factores desencadenantes pueden incluir infección por Mycoplasma Pneumoniae (6) medicamentos (7), condiciones neoplásicas, enfermedad autoinmune y lupus eritematoso sistémico (8).

Siendo una enfermedad poco prevalente aunque con lesiones características, importante en la semiología de la piel, presentamos un caso de EM Mayor

\section{CASO CLÍNICO}

Paciente varón de 36 años de edad, que acudió a emergencias del HNAL por presentar múltiples lesiones tipo úlcera en cavidad oral que no le permitían comer o beber líquidos debido al dolor, asociados a lesiones multiformes en diana en palmas de manos y pies, antebrazos, brazos, piernas, así como también en genitales y región perianal. Las lesiones eran dolorosas con prurito y ardor.

Como antecedente refirió haber sufrido 3 episodios con aparición de lesiones el último año: el primer episodio fue en junio del 2013, cuando presentó lesiones ulcerosas orales que remitieron solas al cuarto día; el segundo en setiembre del 2013, presentó lesiones maculares en miembros superiores e inferiores, remitiendo a la semana; el tercero en enero del 2014, presentó lesiones maculares en codos y manos que remitieron en pocos días.

Examen físico: El paciente se encontraba en regular estado general, buen estado de hidratación y nutrición, lúcido, orientado. En piel encontramos múltiples lesiones papulares eritematosas circulares y multiformes, con centro purpúrico rodeando por hasta tres halos, uno pálido de piel aparentemente sana, otro eritematoso y el más externo eritematoso pálido, de alrededor de un centímetro de diámetro en palmas de mano, a nivel del cuello, tórax, miembros superiores e inferiores pruriginosos y dolorosos, a su vez múltiples lesiones ulcerosas en cavidad oral, (Figura 1). En el examen físico genitourinario encontramos lesiones ulcerativas a nivel de escroto, glande y pene, con sensación de ardor a la micción.

Figura 1. Lesiones ulcerosas en mucosa oral, lesiones eritematosas circulares con centro pálido. Conocidas como lesiones en "diana" o "en tiro al blanco" (A). Lesiones en diana típicas en la región palmar (B)
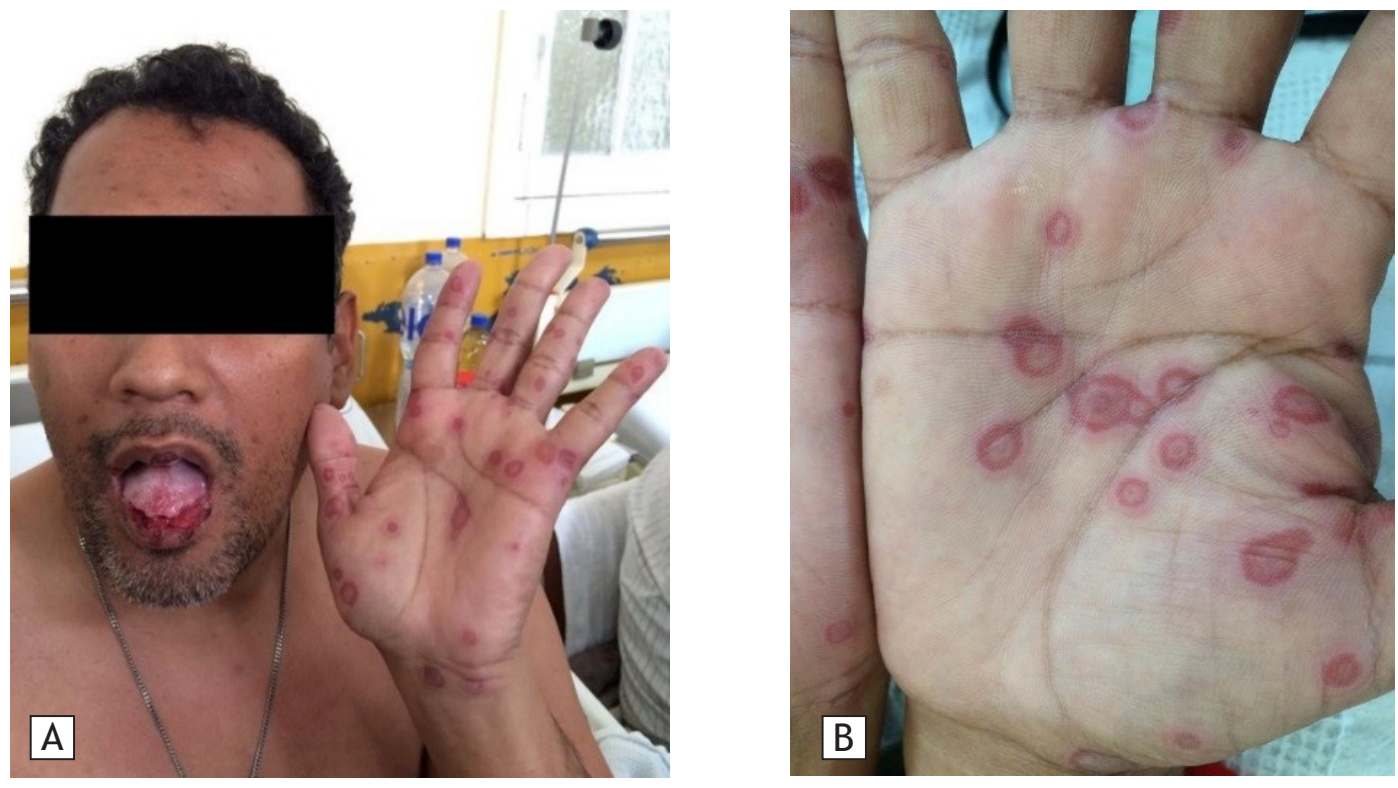
Se realizó una biopsia de palma de mano por punch de 0.3 centímetros de diámetro mayor, siendo el diagnóstico patológico dermatitis de interfase con queratinocitos necróticos consistente con EM (Figura 2).

Figura 2. EM diagnosticado por biopsia de palma de mano. Se observa queratinocitos necróticos, vacuolización basal, y el efecto citopático (C).

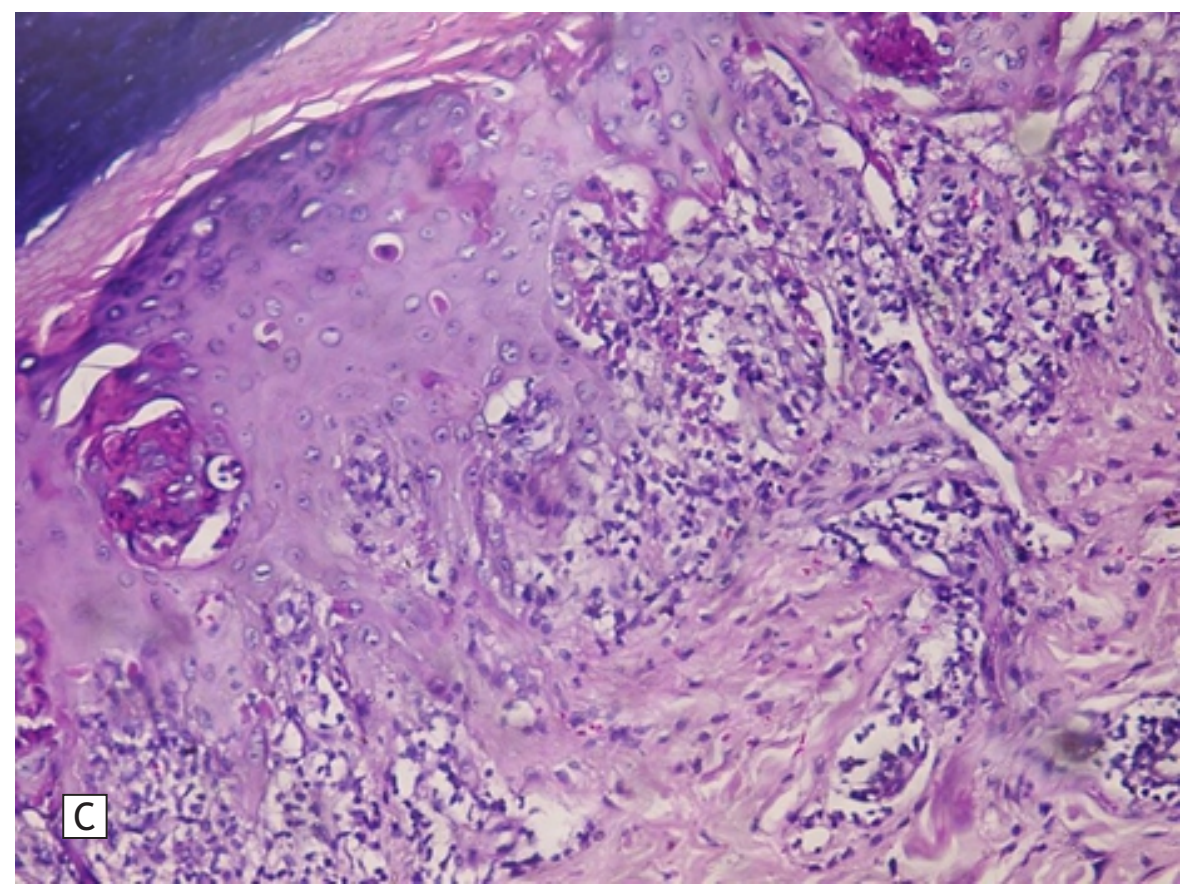

Los exámenes de laboratorio solicitados fueron Anticuerpo IgG e IgM para VHS 1 y Anticuerpo IgG e IgM para VHS 2. Los resultados fueron positivos para el anticuerpo IgG para VHS 1.

El tratamiento administrado fue con Aciclovir 800 miligramos 1 tableta 5 veces al día, con lo cual la apariencia de las lesiones mejoró considerablemente, observándose como secuelas máculas hiperpigmentadas.

\section{DISCUSIÓN}

Según la severidad de la condición, el espectro EM (EEM) se divide en EM menor y EM mayor y se considera actualmente distinto del espectro Necrólisis Epidermoide (ENE) que incluye al Síndrome de Stevens Jhonson (SJS) y a la Necrólisis Epidermoide Tóxica (NET) (3-11).

Se debe tener en cuenta la actual clasificación, definiéndose EM mayor la presentación predominantemente acral de "lesiones en diana típicas" localizadas o "lesiones blanco típicas elevadas" además de múltiples lesiones ulcerosas en 2 o más mucosas; SSJ como la presentación en tórax y abdomen de máculas eritematosas o purpúricas generalizadas o lesiones en diana atípicas planas con desprendimiento menor a $10 \%$ de la superficie corporal ; NET/ SSJ overlap, diferente a lo anterior por el desprendimiento entre $10 \%$ y $30 \%$ del área de superficie corporal; NET con manchas, desprendimiento por encima del $30 \%$ de la superficie corporal más máculas purpúricas generalizadas o lesiones en diana atípicas planas. NET sin manchas, desprendimiento por encima de $10 \%$ de la superficie corporal con grandes láminas epidérmicas y sin mácula purpúricas o lesiones en diana $(12,13,14)$.

El término $E M$ recurrente se refiere a la presentación de 6 episodios en un periodo de 1 año de cualquiera EM Mayor o EM Menor (3). En el EM asociado con infección por VHS tipo 1 o tipo 2, el cuadro clínico aparece aproximadamente de 2 a 17 días (promedio 8 días) siguientes de la reactivación viral $(3,15)$ en los individuos con dichos padecimientos las recurrencias ocurren frecuentemente después de nuevos episodios de infección por VHS (14). Existen múltiples reportes 
que describen la asociación entre EM y VHS. Lozano y cols describieron el caso de un niño de 2 años con parálisis facial periférica derecha asociada a EM por HVS1 tratado con aciclovir endovenoso $30 \mathrm{mg} / \mathrm{kg} /$ día por 7 días (15). Elgueta y cols reportaron un caso de un hombre sin antecedentes patológicos de 22 años diagnosticado con EM con lesiones ampulosas extensas asociado a VHS1 y con predominio de linfocitos CD4+ en la inmunohistoquimica (16). Kampgen y cols encontraron que 31 pacientes con EM inducido por Herpes Simple tenían el antígeno leucocitario humano (HLA) DQw3 aumentado en $77.4 \%$ y había un riesgo relativo de 9.41 de presentar EM (17). Contreras y cols presentaron el caso de una paciente de 24 años de edad, con un cuadro de eritema multiforme secundario a una tiña de la piel lampiña por Trichophyton mentagrophytes var. mentagrophytes adquiridade un animal de laboratorio (18).
Do Carvalho y cols reportaron el caso de un paciente masculino de 29 años de edad con eritema multiforme mayor desencadenado por Norfloxacino con la aparición de lesiones vesiculares-bulloso-ulcerosas en las regiones de los labios, encías, la lengua y la mucosa genital (19).

Es típica la presentación de la enfermedad como el paciente la padeció: Malestar general, fiebre, las múltiples lesiones que brotaron en el curso de tres a cinco días, que se desarrollaron en forma súbita, en diana en palmas de manos y las lesiones ulcerosas en cavidad oral. Cabe resaltar que las lesiones pueden variar de un paciente a otro en presentación y curso. El diagnóstico de EM con este tipo de presentación suele ser sencillo, sin embargo existen condiciones que pueden imitar las lesiones en diana, la más común es Urticaria aguda, que también presenta lesiones anulares, sin embargo en el EM las lesiones son más duraderas (20).

\begin{tabular}{|l|l|}
\hline \multicolumn{2}{|c|}{ Diagnósticos diferenciales de EM } \\
\hline Urticaria & Erupción bariceliforme de Kaposi \\
\hline Síndrome de Steven JonhsonPenfigoide & Dermatosis por IgA lineal \\
\hline Pénfigo para neoplásico & Síndrome de Behcet \\
\hline Síndrome de Sweet & Erupción ampollar por drogas \\
\hline Vasculitis cutánea de pequeños vasos & Síndrome de Behcet \\
\hline Erupción polimorfo lumínica & Síndrome de Rowell \\
\hline
\end{tabular}

Aunque en EM Mayor se espera encontrar elevado rango de sedimento eritrocitario, leucocitosis moderada, y proteínas de fase aguda incrementados (3) el examen leucocitario fue normal. Que hayan habido cuatro episodios de similar presentación y recurrentes revelan que la etiología era infección por $\mathrm{VHS}^{2}$, lo que fue confirmado por las pruebas positivas IgG para HVS tipo 1.

Aunque el diagnóstico de EM es clínico, la biopsia de piel puede ser de mucha ayuda cuando se encuentra, como en la biopsia del paciente, necrosis de queratinocitos (como hallazgo más precoz), vacuolización basal, linfocitos unidos a queratinocitos necróticos y degeneración y licuefacción focal de los queratinocitos basales.

Para iniciar la terapéutica para las lesiones orales, se recomienda una dieta líquida o suave, sin ácidos, que no sea caliente o condimentada. Para iniciar el tratamiento farmacológico en paciente con EM, se debe de investigar el factor desencadenante. Teniendo el resultado de VHS como factor etiológico, se inició tratamiento con Aciclovir. Se conoce que el Valaciclovir y el Famciclovir tienen mayor biodisponibilidad oral que el Aciclovir, aunque este último es preferido para iniciar el tratamiento de EM de etiología viral por VHS, los primeros dos se prefieren en pacientes que no respondan al tratamiento con Aciclovir. Es controversial el uso de corticoesteroides sistémicos, sobre todo en casos de EM recurrente. Cabe destacar que EM recurrente se define como 6 episodios dentro de un año.

En conclusión, el EEM (que incluye Eritema Multiforme menor y mayor) es distinto del ENE (que incluye SSJ y NET). Para distinguir entre EM y SSJ, nos puede ayudar la localización de las lesiones en el primer caso en zonas acrales y en el segundo en tórax. 
El tratamiento de un episodio agudo de EM varía de acuerdo a la etiología (la presencia o ausencia de enfermedad recurrente) y la severidad de la erupción aguda.

El aciclovir ha demostrado reducir las lesiones y la sintomatología del EM, siendo este el medicamento de elección. El uso de corticoides aún es controversial.

En pacientes con EM recurrente, el agente causal debería ser identificado y eliminado. Para los pacientes con EM por HSV o EM idiopático que presentan más de 6 episodios por año o tienen menos episodios pero con compromiso severo, se recomienda un tratamiento antiviral continuo de al menos 6 meses. Recordar que realizar una buena historia clínica y examen físico son los instrumentos indispensables para un lograr una presunción diagnóstica asertiva.

\section{Agradecimientos}

A los doctores: Cesar Chian García (Departamento de Patología del Hospital Arzobispo Loayza) y Dayer Larrea (Departamento de Dermatología del Hospital Arzobispo Loayza) por su colaboración en la obtención de las microfotografías patológicas y la descripción de las mismas.

Al Doctor David Loja, por las recomendaciones en la edición.

\section{REFERENCIAS BIBLIOGRÁFICAS}

1. Kempton J, Wright JM, Kerins C, et al. Misdiagnosis of erythema multiforme: a literature review and case report. Pediatr Dent 2012; 34(4):337-42.

2. Huff JC, Weston WL, Tonnesen MG. Erythema multiforme: a critical review of characteristics, diagnostic criteria, and causes. J Am Acad Dermatol 1983; 8(6):763.

3. Fitzpatrick's Dermatology in General Medicine. 7th edition

4. Manganaro AM. Erythema multiforme. Gen Dent 1996;44:164-6.

5. Watanabe R, Watanab H, Sotozono C, et al. Critical factors differentiating erythema multiforme majus from StevensJohnson syndrome (SJS)/toxic epidermal necrolysis (TEN). Eur J Dermatol 2011; 21(6):889-94.

6. C Léauté-Labrèze, T Lamireau, D Chawki, J Maleville, A Taïeb Arch Dis Child. Diagnosis, classification, and management oferythema multiforme and Stevens-Johnson syndrome 2000; 83:347-352

7. Reacciones Adversas a Medicamentos en Dermatología Vol. 13 N³ Julio 2002. Revista Médica de Clínica Las Condes

8. Maira Mukai; Michelle Tokarski; Marilia B. Silva; Thelma L. Skare. Síndrome de Rowell e lúpus eritematoso sistêmico: um diferencial Rev. Bras. Reumatol. São Paulo May/June 2003; 43(3)

9. Ayangco L, Rogers RS. Oral manifestations of erythema multiforme. Dermatol Clin 2003; 21:195-205.
10. The Link between Hypersensitivity Syndrome Reaction Development and Human Herpes Virus-6 Reactivation

11. Recurrence and Outcomes of Stevens-Johnson Syndrome and Toxic Epidermal Necrolysis in Children

12. Wetter DA, Davis MD. Recurrent erythema multiforme: clinical characteristics, etiologic associations, and treatment in a series of 48 patients at Mayo Clinic, 2000-2007. J Am Acad Dermatol 2010; 62:45-53.

13. Bastuji-Garin S, Rzany B, Stern RS, Shear NH, Naldi L, Roujeau J. Clinical Classification of Cases of Toxic Epidermal Necrolysis, Stevens-Johnson Syndrome, and Erythema Multiforme. Arch Dermatol.1993; 129(1):92-96.

14. Saldaña L, Ponce M, Urticaria aguda. Rev. Dermatol Perú 2012. 22(1).

15. Lozano G., Ramos J.M. , Moreno E. García Martín F.J Parálisis facial asociada a eritema multiforme por virus del herpes simple Anales de Pediatría 2011; 75(3): 210-212)

16. ELGUETA-NOY, A et al. Eritema multiforme ampollar extenso asociado a infección por virus herpes simplex. Rev. argent. dermatol. [online]. 2009, vol.90, n.4 [citado 2014-12-05], pp. 00-00. Disponible en:<http://www.scielo.org.ar/ scielo.php?script=sci_arttext\&pid=S1851$300 \times 2009000400003 \&$ lng=es\&nrm=iso>. ISSN 1851-300X.)

17. Kämpgen E, Burg G, Wank R. Association of Herpes Simplex Virus-Induced Erythema Multiforme With the Human Leukocyte Antigen DQw3. Arch Dermatol.1988;124(9):13721375. doi:10.1001/archderm.1988.01670090028005.

18. Contreras M, Moreno G, Torres E, Aguilar A, Arenas R Eritema multiforme secundario a infección por Trichophyton mentagrophytes Rev Iberoamericana Micol, 2009; 26(2):149151

19. de Carvalho Raimundo Ronaldo, de Santana Santos Thiago, da Silva Filho José Paulo, Guimarães de Melo Albert Daniela, Dias de Oliveira e Silva Emanuel, Amorim Gomes Ana Cláudia. Eritema multiforme mayor desencadenado por antimicrobianos. Rev Cubana Estomatol [revista en la Internet]. 2010 Mar [citado 2014 Dic 05] ; 47(1): 115-121. Disponibleen: http://scielo.sld.cu/scielo.php?script= sci_arttext\&pid=S0034-75072010000100010\&lng=es.)

20. Schofield JK, Tatnall FM, Leigh IM. Recurrent erythema multiforme: clinical features and treatment in a large series of patients. Br J Dermatol. 1993; 128(5):542.

Fuente de Financiamiento

Este artículo ha sido financiado por los autores.

\section{Conflictos de interés}

Los autores declaran no presentar ningún conflicto de interés.

\section{Correspondencia:}

Aníbal Alonso Manrique Acha

Dirección: Calle Nestor Bermudez 119 Urbanización San Juan -

Chorrillos - Lima, Perú

Teléfono: 980902788

Correo electrónico: anibal_ma@hotmail.com
Recibido: 28 de setiembre de 2015 Aprobado: 12 de octubre de 2015 